\title{
The commodification of information
}

\section{J.E. TRAUE}

$\mathrm{T}$ HE COMMODIFICATION OF INFORMATION is not unique to New Zealand. We may have added some home-grown aberrations in the public sector due to the ideological purity of, and the power wielded by, our Treasury, some domestic absurdities in central and local government as lesser minds have attempted to translate the dogmas of commercialisation into policies for real institutions such as libraries and archives, but the movement towards the commodification of information is an international phenomenon which has gathered pace in the past forty years or so. However, one could claim with some justice that the transformation in New Zealand has been faster and more complete. We began late but within ten years a revolution has been accomplished. The assumptions about the public interest have been overthrown and public sector institutions reformed to build the new assumptions into everyday activity.

The literature on the information society and the commodification of information is vast, diffuse and inconclusive. Even information itself is defined differently by economists, engineers, librarians and sociologists.

To help negotiate this maze we need to look at the wider issues, at the characteristics of the long term international trend towards the commodification of information, before moving to an examination of particular manifestations in New Zealand since the advent of Rogernomics in the mid-1980s.

In oral cultures information is inseparable from knowledge. There is no tangible thing which exists outside the memory of individuals that we can identify as information.

With the advent of writing it became possible to create a tangible thing outside the minds of people, and the split between information and knowledge began. A written text was tangible, storable, inscribed on some physical medium, portable, and as an object potentially tradeable, like food, clothing, adornment, weapons and utensils. Initially in literate societies texts served as aide-memoires and for divine messages as a fixed set of words safe from the corruptions of memory. But written texts were still regarded as inferior to the internalised knowledge held in memory. Memorisation was still the norm.

With the advent of printing from moveable type in Europe in the 15th century the first major step towards the commercialisation of knowledge in books was taken. It was now possible to turn an art form into a craft and to mechanise it to produce true multiple copies. The num- bers of printed texts within the first 50 years of printing exceeded all the manuscript texts produced in the previous 1,000 years, and costs fell substantially.

With the rapid success of printing in flooding the markets with packages of information, and the development of indexes and bibliographies to organise and control these packages, the older emphasis on knowledge, on the internalising of information in memory, began to decline and the division between knowledge and information as an external, neutral, tangible, marketable product, became more widely accepted in the public mind.

With the first commercialisation of knowledge in books around the new printing and publishing industry it soon became necessary to give the protection of the law to the new products of men's minds. In ancient and mediaeval times the borrowing of ideas, even the exact form of expression in words, was free and unrestricted. Formal acknowledgement was unnecessary, the learned audience would immediately recognise the borrowing and congratulate the writer on his knowledge of the writings of the masters. In the new information industry of printing and publishing it was necessary to protect the intellectual property resident within the information packages. The Statute of Anne of 1710, the first British Copyright Act, recognized the existence of an intellectual property right and assigned it to the author as creator.

What is not often recognised is that the Statute of Anne was deliberately aimed at the unpopular monopoly rights in publications claimed in perpetuity by the publishers, which it extinguished, and was an assertion of the public interest in the free flow of new knowledge. Authors were to be given a limited ownership right, strictly limited in time (14 years, extendable to a maximum of 28 , after which it reverted to the public domain) and limited in scope - more like a licence than outright ownership because it was deemed necessary to protect the author's potential income from his efforts in order to promote a higher good, that is the creation of new books. Additional clauses in the Act provided for price controls to prevent this limited legal monopoly being abused to the detriment of the public interest. The title of the act reveals clearly the priority: An act for the encouragement of learning by visiting the copies of printed books in the authors.

The idea behind this first copyright legislation, that society has a legitimate interest in access to newly created knowledge and that the state should intervene to ensure that the public interest is enhanced by the increasing commercialisation of knowledge in books, is one that un- 
folded during the 18th, 19 th and early 20 th centuries. The courts, initially, read into the Copyright Act the concept of fair dealing, that it was not only legal but in the public interest that those who were adding to new knowledge should be able to borrow freely from others in the process of review, research and private study, and this concept was in due course incorporated into the legislation itself.

Parallel to the development of the legal protection of intellectual property was the developing idea of plagiarism. In ancient and mediaeval times the ruling concept was that of the information commons, of information held in common ownership and accessible according to rules sanctioned by the customs of the community. In early modern times the ruling concept became much more that of a commons under government trusteeship, with the trustee guaranteeing certain limited intellectual property rights to authors (and by transference, to publishers) because it was seen as being in the public interest.

As well in early modern times another mechanism, under central and local government trusteeship, was developed to facilitate the public interest by enhancing public access to the growing flood of information in the marketplace. The mechanism was the public library. Initially private collections made available to the public under the legislation governing public charities, then university collections open to all members of the learned community, then national libraries funded by central government and open to the learned community, and then the truly public library supported by local taxation and in many countries, notably New Zealand, subsidised by central government as a public good. The public purse was employed to create public enclaves where the accumulated knowledge in books was in principle available to all citizens.

By the mid-20th century the new ways of thinking about information were endemic. Information was now perceived as quite distinct from its package - the book an idea which was revolutionary in the 17th century. Information had become the common essence for things as distinct as an electrical impulse, an equation, a name, a table of figures, an essay, a novel, a poem and a picture. Now this way of conceptualising can be a powerful analytical tool but it can also mislead. Shakespeare and Milton and railway timetables and tide tables are all information and in the simplistic reductionism of our times they are being held to be equal in value as information.

This new idea of information, and it is a distinctively 20 th-century development, is the foundation of the concept of the information society and the information economy, and it made information ripe for the leap into commodification. It was not the technology alone that made the leap possible. Technology, in the form of the computer with its extraordinary capacity to store and manipulate information, and the marrying of the computer to telecommunications so that information could be moved almost instantaneously anywhere in the world, was critical, but it was also necessary to conceptualise the significance of the change.

The critical points in the mid-20th century leap in thinking are Shannon and Weaver's Mathematical Theory of Communication, the formulation by Oettinger and others of information as a resource, and Daniel Bell's The Coming of Post-Industrial Society. ${ }^{1}$

Shannon and Weaver analysed signal transmission in engineering and modelled the process whereby a signal is encoded by a sender and decoded by a receiver. They came up with a formulation of the measure of information as the logarithmic function which expresses the choice of one message from the set of all possible messages. What is critical is that they isolated from the technology a measurable entity, which they called information, distinguishable from who moves it and how it moves. So separated, information can be easily quantified, and this opened the way to the exact measurement of electronic information passing through a computer, and by extension, all information.

Knowledge, as distinct from information, had always presented problems for the bean counters. It is imprecise because it involves both an individual's abilities and motivation to internalise information. It also has a substantial qualitative dimension which makes it even more elusive for the quantifier. Information, now conceived of as a thing, is much more tractable and Shannon and Weaver were seen as providing the theoretical underpinning for the precise measurement of information. What you can measure you can put a price on and sell.

Oettinger and others took the next step by defining information as a resource that could be consumed or used to add value to existing resources by making industrial processes more productive and by enhancing the provision of services. Information, in his formulation, is a valuable raw material in its own right and can add value to the existing factors of production, that is labour, capital and other raw materials. Information, however, has a unique characteristic in that it is a non-depletable resource. These ideas were particularly appealing after the first oil shock in the 1970s when issues of resource depletion and the control of essential resources, like oil, were very much in the minds of economists. Strategists and economists seized on the idea that information was the new wonder resource, and that because Western economies were rich in this seemingly inexhaustible resource it would be the means of maintaining economic and political leadership. In this landscape intellectual property rights loom even larger, and it is no accident that the United States and the European Community countries are currently assiduous in the field of the international control of intellectual property.

The third major influence is that of Daniel Bell and his Coming of Post Industrial Society, one of the first major attempts at a theoretical explanation of the trends. Bell's thesis is that the industrial society which had developed 
in the 19th century was being replaced by a post-industrial society. Broadly speaking, if industrial society is based on machine technology, post-industrial society is shaped by intellectual technology. And if capital and labour are the major structural features of industrial society, information and knowledge are the major structural features of post-industrial society.

In this post-industrial society theoretical knowledge, knowledge workers, and above all information, are the prime drivers of the economy and of society as a whole. Bell suggests that in this new economy the old scarcities of material resources will be of lesser concern and that the new scarcities will be of information and time. Most of the developers and popularisers of Bell's ideas have seen the new society as one flooded with easily accessible information. At last, with information liberated from its containers and digitized so that it can flow down telephone lines the dream of universal access to information has at last become a reality. Information is now potentially accessible to all outside the walls of institutions through the new technology, and the costs of technology are falling so fast that electronic information will be so cheap that it will not be worth the bother of trying to charge for it.

There is another and more realistic interpretation of the new information economy, what Vincent Mosco calls the 'pay-per society'. ${ }^{2}$ The utopia of freely accessible information for all is receding further and further into the never-nevers as the pay-per-use information economy accelerates. What we can now see is an acceleration of tendencies at work for the last few hundred years, a deepening and extension of the logic of the marketplace, a process of making all social life, including such basic components as time, space and information, into marketable commodities. Information is moving away from a commons under government trusteeship towards private property under individual, and increasingly corporate, ownership and management. Pay per call, pay per view, per bit of information, per keystroke, turns every information transaction into a financial transaction, where the marketplace rather than political power determine allocations, where people's information needs are no longer determined by public policy but by the market.

The ideas underpinning this change were being fleshed-out in the United States in the 1970s and were widely implemented by the Reagan administration in the 1980s. ${ }^{3}$ The Information Industry Association produced reports on the need to recognise information as a commercial product and to promote the development of private enterprise in the field of information, and a series of reports published by the National Commission on Libraries and Information Science (NCLIS) in the late 1970s and early 1980s argued for the dismantling of the national government supported structures for public information supply. Government agencies were urged to hand over dissemination of government information to private en- terprise and it was argued that if the market could provide government should no longer be involved. Under Reagan a range of federal publications were sold to private enterprise, with substantial increases in costs to buyers, almost a quarter of federal publications were discontinued, thus reducing the amount of information available to libraries, and large areas of information gathered by government were transferred to private enterprise for added value processing and sale (often the added value was little more than providing printouts from government databases at a hefty cost). The 1985 Office of Management and Budget Circular A-130, 'Management of Federal Information Resources', declared that "information is not a free good but a resource of substantial economic value and should be treated as such", and laid down the principle that government agency information programmes were to be limited to those the private sector was unlikely to adopt and drew firm distinctions between the provision of access on demand by the public and dissemination through publication by government which was to be strictly limited.

By now you should be able to appreciate what has happened and is continuing to happen in New Zealand. The destruction of public radio and its replacement by one driven by commercial imperatives, the drive to commercialise as many as possible of the transactions at your local public library, the pressures on the National Library and the National Archives to fund an increasing amount of their activities out of user charges, are a logical consequence of the new information economy.

To Treasury officers or consultants to local government (often ex-Treasury officers) educated to believe that information is a resource, that it is the driving power of the modern information economy, and that no matter what format it happens to be in it is information capable of being sliced into measurable pieces and priced for sale, the vast accumulations of books, periodicals, archives and manuscripts in our publicly funded libraries and archives look like gold mines ripe for exploitation. How is it, they puzzle away, that these gold mines currently pose a risk to government and are so unproductive, that they are almost wholly dependent on the public purse and are recovering substantially under $10 \%$ of their running costs. Inefficiency, user capture, capture by the professional culture of the staff, and downright perversity have all been flagged as culprits and measures devised to correct the situation. The thought that these institutions may possibly serve a different function in society, that of protecting the public interest in the availability of information, is never contemplated.

The Treasury analysis of the National Library serves as a model of the pattern of thinking. In 1994 Treasury prepared a discussion paper to guide the National Library's thinking for its 1994 Strategic Plan. ${ }^{4}$ You may recall that the National Library, and its predecessor the Country Library Service, were established as instruments of public policy to improve national access, not to information but to prosaic 
books and periodicals. The National Library would identify the national resources and coordinate their sharing between the rich and the poor, that is the resource-rich big city public libraries, government and university libraries, and the poor small town libraries. In addition it was to build a national collection, available to all, to soak up some of the demand from the poor but also to ensure, in the words of G.T. Alley, that every worthwhile book was purchased and held in New Zealand.

The Treasury prescription was that those collections for equalising national access should be disposed of or managed for full cost recovery. For the General Collections the advice was that it is unlikely that Government has purchase or ownership interests. The library should consider cost recovery for this output and devolving ownership to other libraries (ie, selling the collections) in the medium term. There is no apparent market failure that requires a government intervention for either the management of the collections or the supply of documents to clients. Because of the growth and strength of local authority libraries traditional barriers to access to information have been reduced. A separate purchase intervention by the Government may unnecessarily duplicate existing services.

For the Schools Collection, again set up to provide equalisation across the country, the recipe is to fund the schools to purchase services at full cost recovery in a competitive market, that is a funder/provider split with full competition. In the long term, as the market develops with a host of competing suppliers, the National Library should sell off its schools collections to these suppliers.

As for the reference services, that is the provision of guidance and advice, the identification of useful material and the answering of questions, again government is unlikely to want to buy these services. The National Library is advised to move towards full cost recovery because the failure to charge a price which covers costs is crowding out suppliers of alternative information management products, encouraging over-use of resources, and discouraging dynamic development of competitive products.

The Government may have an ownership interest in the bibliographic network, the electronic network connecting all the major libraries in New Zealand, a major cooperative cataloguing and location tool, because it is a natural monopoly, but only in the medium term until the market matures. The alternative favoured is club ownership, that is ownership by the cooperating libraries, in order to reduce the risk involved in Crown ownership.

You will be relieved to know that the heritage collection, the Alexander Turnbull Library, is safe in the meantime in this new lean mean National Library. Government should continue to own the core New Zealand heritage collection but maintaining non-New Zealand heritage collections is of lower priority and consideration could be given to scaling them back over the medium term. However, consideration should be given to greater cost recovery for access to heritage collections (my calculation is that in 1994/5 recovery for the Turnbull was $4.9 \%$ of costs compared with $9.8 \%$ for the whole National Library, and this was up $5 \%$ on the previous year, an achievement which earned considerable space, with diagrams, in the National Librarian's annual report for that year). Individuals and researchers, it was conceded, could be allowed free access to the heritage collections to achieve Government's cultural objectives, but full cost recovery for access services for commercial users should be considered.

These individual non-commercial research users are to be assigned a lower priority in the Turnbull's access outputs. Treasury considered that the access outputs should be focused primarily on basic access to other information providers, that is middlemen, who will buy from the Turnbull and add value by transforming their purchases into forms that final users may wish to purchase:

This could be done by franchising or licensing private information providers to access and transform the [Turnbull's] information base.... Requiring full cost recovery for all value added services provided by the Library beyond basic access to the Collections ... will encourage providers to develop services in competition with the Library. (p.10)

One of the National Library's responses to the Treasury's demand that the National Library move towards full cost recovery was to recruit a raft of five senior market managers, mostly from private enterprise, rewarded at almost twice the level of experienced professional librarians. Below the chief market manager, who became a member of the senior management team, were four other market managers; for individual users, for schools, for business, and for other libraries, and the reference staff of both the Turnbull and the National Library, the exhibition gallery and its staff, and reception, were moved under the control of the market manager for individual users, or consumers, as they are now conceptualised. Other staff responsible for providing access to the collections and services also report to market managers. Their roles, one assumes, is to sell to us as consumers what we have already paid for as taxpayers

The Turnbull has also moved aggressively into the marketplace with a service to provide images from its collections on the Internet, at a price. Paul Reynolds, in the Infotech Weekly in the Dominion newspaper for $3 \mathrm{March}$ describes it as "trading in NZ Heritage". Reynolds admires the professionalism but points out that commercial considerations have overwhelmed issues of cultural sensitivity and the integrity of the items. His final comment is: All this fills me with despair. If the likes of the Alexander Turnbull Library can't come up with a more coherent and imaginative use of the Internet than making money out of the production of tea-towels, then every other digital author with a shred of 'sensitivity' might as well give up!

The Treasury rationale for Government having a continuing ownership and funding interest in the Turnbull is worth exploring. Because the market for cultural heritage 
is characterised by high costs and a relatively low level of demand, the market will not deliver cultural heritage outputs to the level the government thinks appropriate. Heritage collections are not, however, a public good because people can be excluded from using them, but they may be a merit good. As a purely merit good, Government's purchase interests, Treasury warns, need to be weighed against other cultural priorities and the relative priorities given to cultural spending against the overall fiscal objectives of reducing government expenditure. So, somewhat reluctantly, due to the soft-headedness of Government over cultural matters, the Turnbull is given a reprieve, but at a price.

However, we expect that there will need to be ongoing productivity improvements, to ensure that the price of this output falls along with the costs of other outputs being purchased by the Government elsewhere. (p.9)

That is, Turnbull may be allowed to survive, provided that its cost to government keeps on falling, that is that less of the taxpayers' money is spent on Turnbull in the future. The natural growth of the Turnbull's collections, and the increasing cost of storing, conserving and organising the collections, rather than being encouraged, is likely to be punished under this scenario. This fixation on a constantly reducing government expenditure on library and archival institutions will appear later in my consideration of the commodification of National Archives.

There are some very telling linkages in the document to the set of ideas I outlined in my introduction, and another stance worth noting, that of a rigorous matching of the institution's outputs with government priorities, to which I shall return in my conclusions.

The government's stated 'outcome objectives' from the 1992 Budget annex Economic Strategy are summarised. The National Library's objectives have to be aligned very specifically with the overall government objectives:

The linkage of the National Library to these economic policy objectives is based on the importance of information for economic decision making. An economy runs on knowledge, and on the efficient working of processes to do with knowledge. The processes involved include: The creation, discovery and noticing of new knowledge; the spread of knowledge through society by learning, information transfer, information storage and retrieval and so on; the filtering of ideas and of enterprise to use these ideas, and; the coordination of economic and commercial ideas. The nature and scope of the government's purchase and ownership interest in the National Library should be to promote the efficient creation and dissemination of knowledge. This includes limiting it to cases where there is evidence of a market failure, and where the National Library is the most efficient mechanism available to Government to overcome this failure. In any case the imperfect operation of the market is a necessary but not sufficient condition to support an intervention by the National Library. (p.3) $^{3}$

The document then analyses the information market and the place of libraries:

The information market needs to meet dual objectives.
First, to produce and compile the greatest amount of valuable information as possible and second to distribute that information as widely as possible. ... Since new information is costly to both produce and disseminate it is important that there are appropriate incentives to encourage the right amount of development and dissemination, and ensure that it is most suited to users changing needs. One way to encourage innovation, and the disclosure of discovered information, is through allocating private property rights over information, such as patents, copyrights etc. ... Efficient dissemination is achieved by organising this information in databases and marketing to potential users, who pay for this service. This allows access to information directly by clients regardless of geographical distance, and for them to be charged according to the costs of servicing them .... Providing charging regimes can be operated without undue transaction costs, the purchase benefits to the Crown we foresee ... include: Better library services which are more responsive to users needs; allowing more effective targeting of library related assistance to those clients who need it most; encouraging clients to use alternative providers of library based information services, such as regional libraries where this is more efficient; saving costs by promoting more efficient allocation of resources including more informed decision making by both the Library and users. ${ }^{\text {(p.) }}$

The paper rules out information as a public good which should be provided free of charge by government, declares that the externalities are likely to be private and should be paid for by the user; and dismisses the argument that it will unduly restrict use by poorer people. It argues that the more cost effective intervention to address equity concerns is to target assistance to such poorer users as exist. No doubt a means-tested ticket, like a bus ticket to be clipped as you enter, is under consideration for the poor.

I make no apology for spending so much time on this document, and for extensive quotation and summarising. It is the best and fullest expression that I have been able to find of the "information-as commodity-in-a-competitivemarketplace" argument in New Zealand. Some of you might not have believed me if I had given you my interpretation of it, and as well you need to savour the arguments and the prose. The document doesn't qualify as a textbook, but it certainly exemplifies the application of a textbook mentality. Unfortunately for us Treasury has but one textbook and recalcitrant institutions have to be cut twisted and squeezed to fit its assumptions.

The same kinds of assumptions, but not so baldly expressed, lie behind the forthcoming reforms of public libraries in New Zealand. The major impetus is the privatisation of local government services and the current thrust derives from the Local Government Amendment Act No 3 1996 which requires Councils to review all of their activities and to work out who benefits and who should pay, and to assess the level of public and private benefits from these activities. Bob Edlin, in a scathing attack in the Independent of 28 February, 'Rationalising private and public ratios', claims that the obligation to quantify public benefit:

"looks like the product of a mind-set hell-bent on slapping a price tag on everything while spurning the value of 
anything ... it paves the way to greater privatisation because it's easier to make a case for selling Council assets where figures - no matter how shonky - are bandied about to contrast public cost and notions of private benefit. ... (It is) number stretching, because the data are as elastic as a bungy jumping cord ... as politically rancorous as it is economically barmy".

Councils throughout New Zealand are attempting to value their public library services, on the assumption that they deal in information which is a measurable thing and can be priced, and arriving at figures ranging from $5 \%$ to $75 \%$ private good, and this percentage of the library's costs is then to be met from charges on the users.

In Wellington the councillors began trying to count the number of angels on the head of a pin: they had determined initially that the 'entertainment' content in the public library's collections was $25 \%$ public good, while the 'information' content was $75 \%$ public good, and charges should be levied accordingly for entertainment or information. They suspected that there might be a few problems in the implementation (Shakespeare was admitted as a problem), but were firm in the belief that all this is measurable. In early March they retreated to a simple $90 \%$ public good, $10 \%$ private good estimate of the library's value, later moved to a $75 \%$ public good, $25 \%$ private good, and finally decided that $10 \%$ of the funding should come from the users and $90 \%$ from the rates. Such swings, based on political judgements, testify to the instability of these figures.

As the economist John Lepper (quoted by Edlin) has pointed out the quest to define public and private goods isn't that helpful, the real question is what is in the public interest. But that's a very old fashioned concept.

The Wellington Public Library has also had to adjust its 'vision' to fit the new model of the City Council as a competitive business. The new emphasis for the library's business is on sales, on meeting competition, on aggressive marketing, on detailed analysis of borrowing patterns to meet expressed consumer needs, efficiency, profit and return on investment. The new business vision is to be "The first choice of Wellingtonians seeking to enjoy and benefit from fact and fiction", a declaration of market dominance worthy of any producer of soap, toothpaste or detergent, which if they really mean it would produce open competition with the university, polytechnic and national libraries, every school library in Wellington, with bookshops, newspapers, movie theatres, television and radio. It is the creation of a bogus market the pursuit of which will deform the core goals of a public library and turn it into an information emporium selling information to those who can afford it.

The next example worth analysis is the proposed reform of National Archives to make it conform to the model of a competitive business in the private sector. The financial performance of National Archives is marginally worse than that of the Turnbull. In $1992 / 3$ it raised only $6.4 \%$ of its income from user charges, the rest of its revenue came from government. Worse still, the size of its collections had grown rapidly in the 1980s, requiring greatly expanded accommodation, and all indications were that the cost of its growth, in new buildings, staff and equipment, would outstrip its earnings from user charges in the foreseeable future. Worse still, the size of the gold mine was even bigger than the Turnbull, a staggering valuation of some $\$ 700-800$ million. A $6.4 \%$ return on the revenue provided by government, and an infinitesimal return on the capital asset, was a clear indicator of poor financial management.

The recipe was simple. A Treasury-induced consultant's report pin-pointed the "financial risk" to which government was exposed - that is, the natural growth of National Archives would require additional government funding each year, not less - and proposed the usual medicine: restructuring, a policy advice/provider/funder split along the lines of the reforms in the public health sector (may God rest their bones), an advisory (ie, management) board of business-oriented lay-people, a more business-like internal culture to replace the archives culture of the professional staff, and the removal of the day-to-day custody, care and control of the archives from the Chief Archivist and the placing of these functions in the hands of a new Business Manager. The hidden agendas were only too obvious: reduce the rate of growth of the collections, and if possible the total size of the collections; in the short term raise the charges on users to generate more income; and in the medium term encourage the development of a competitive market by raising to the market rate the charges for government agencies to store their archives in National Archives.

The reforms in broadcasting, which have dismantled an organisation oriented to public service, with the objectives of informing, educating and entertaining, and replaced it with a servant of the market, a cash cow designed to enrich the state ( $70 \%$ of the $\$ 50$ million profit in 1994 was paid to government) the broadcasters and the advertisers, has been examined in detail by several observers, and I would recommend Paul Smith's Revolution in the Air. The principles are familiar: broadcasting is a business like any other business, selling a commodity no different from baked beans, in which the consumer's choice is the only measure of value. Social and cultural values, and matters of national identity should be left to the marketplace, and if there is market failure government or other external agencies should purchase the cultural or national identity outputs they desire in open competition with the advertisers. The only choice offered is quantitative, effectively more of the same, and qualitative choice, the most valuable of all, is being squeezed out of the system. And to underline the stance that broadcasting is no different from baked beans the Broadcasting Amendment Act of 1991 allowed $100 \%$ foreign ownership of any broadcasting outlet.

The commodification of information is a necessary step on the road to its privatisation. Privatisation is not 
just the move to sell-state owned enterprises, it is something much more fundamental. It is the desire to reform, or dismantle if necessary, those organisations which appear to be operating in the public interest and to replace them with organisations dedicated to purely private interests, on the grounds of increased effectiveness and efficiency. The model is that of the private business firm hypothesized by economic theory, geared to respond with maximum efficiency to clear economic signals from its external environment and to do nothing else. In this brave new world a separate public interest is not just an impediment to private interests, it is superfluous. The wholehearted pursuit of private interests, rigorously defined in terms of private economic benefits will, it is claimed, automatically achieve the optimum public good.

Closely related to this extreme form of economic rationalism is the desire for clarity of purpose, a theme to which I promised to return. You will recall Treasury's insistence that the National Library's objectives had to be highly specific and closely aligned with the very explicit 'outcomes objectives' for the government as a whole. Institutions in the public sector, the voluntary sector and the private sector are all redefining their roles to concentrate on what they conceive to be their 'business', and in so doing are inevitably narrowing the focus of their activities. Echoing Peter Drucker's classic phrase, 'What is our business and what should it be', executives and boards of management and trustees and governing bodies are reforming their organisations to shed the woolly and the superfluous in order to concentrate on their core business. You will all by now be familiar with the apparatus of the revolution; instead of the guillotine, the mass trial and the firing squad we have the vision statement, the mission statement, the core objectives, the strategic plan.

For all these organisations the imperative is effectiveness, to do even better the job for which they were created and to eschew all irrelevancies. However, in many organisations in central and local government the real concern is not effectiveness at all, it is the shifting of costs from government, no matter what the consequences, or as it is expressed with maximum obfuscation by Treasury policy analysts, reducing the financial risk to which government is exposed. No doubt some gains are made as organisations concentrate their resources on a narrow range of precisely formulated objectives, and no doubt society in general benefits from the planned outcomes of increased effectiveness and efficiency in carrying out their daily operations, but in the process we are losing something that may be even more important.

That something which is being ruthlessly squeezed out of the vision of so many of the organisations that define our society is the concept of the common good. The efficiency of the postal and communication services, radio and television, the railways, shipping, the health services, education, libraries, archives and welfare have improved as they concentrate on their core business, but this single minded concentration of efficiency has been bought at a price, and that is the health of the total society.

If the larger system, that is society, should falter and fail, the subsystems will be brought down as well, no matter how focused they are. No matter how effective and efficient they are within their narrow focus they will fail despite their strategic plans and visions. This of course was the understanding we had reached in advanced democratic western societies by the end of the Second World War, that the price of the autonomy and self-preoccupation of both individuals and organisations in a free society (that is the price we willingly paid in order to go about our lives and our businesses as we saw fit) was that individuals and organisations all had to make their contribution to the common good. It may have been messy, it was certainly inefficient and it could not be quantified, but the health of the body politic required that kind of investment in the public interest, by everyone, both individuals and organisations.

I think most people would agree that the free flow of information is too important to be left to the mercy of elites, whether religious or political. Equally it is too important to be left to the mercy of the market and those who have market power. The increasing commodification of the production and dissemination of the knowledge accumulated in books since the application of printing in Western societies had produced a countervailing power, that of the community, whether represented by central or local government, acting in the public interest either as a regulator or a provider, to widen access beyond the power of the individual purse.

Digital technology and telecommunications have substantially increased the potential for further commodification and that potential has been abetted by the shift to conceptualising information as a common essence and as a resource, but it is the ideology which holds that the unfettered market is the only instrument for managing social and cultural life (and which is pushed to its bizarre limits by the New Zealand Treasury) that has tipped the balance away from the public interest well towards the private interest, and in the long term we shall all be the poorer for it.

\section{NOTES}

1 ClaudeE.Shannon and Warren Weaver, The Mathematical Theory of Communication (Urbana:University of Illinois Press, 1949); Anthony G. Oettinger, "Information Resources: Knowledge and Power in the 21st Century", Science 209 (4 July 1980), 191-8; Daniel Bell, The Coming of Post-Industrial Society. A Venture in Social Forecasting (New York: Basic Books, 1973)

2 The Pay-per Society. Computers and Communication in the Information Age. Essays in Critical Theory and Public Policy (Norwood, Ahlex, 1989).

3 Donna A. Demac, "Hearts and Minds Revisited: the Information Policies of the Reagan Administration", in The Political Economy of Information, 125-145 (Madison; University of Wisconsin Press, 1988)

4 New Zealand Treasury. Discussion Paper: The Nature and Scope of the Governments Purchase and Ownership Interest in the National Library, 23 February 1994. Unpublished, 16p. 